\title{
A new TPE-based foam material from EPDM/PPB blends, as a potential buffer energy-absorbing material
}

\author{
Z. X. Zhang, Y. M. Wang, Y. Zhao, X. Zhang, A. D. Phule* \\ Key Laboratory of Rubber-Plastics, Ministry of Education/Shandong Provincial Key Laboratory of Rubber-Plastics, \\ Qingdao University of Science and Technology, 266042 Qingdao, China
}

Received 26 April 2020; accepted in revised form 26 June 2020

\begin{abstract}
Blends from the thermoplastic elastomer (TPE) of Propylene/1-butene copolymers (PPB) and Ethylene-propylene-diene monomer (EPDM) were successfully prepared by melt-mixed in an internal mixer and crosslinking through highenergy electron beam irradiation technology. The foaming process was achieved with the assistance of eco-friendly supercritical carbon dioxide $\left(\mathrm{sc}-\mathrm{CO}_{2}\right.$ ). The effect of EPDM content on foaming, morphology, thermal, and mechanical properties of EPDM/PPB blends with varied irradiation dose were investigated. Microstructural analysis revealed a perfect compatibility of PPB and EPDM in TPE. The increased EPDM content caused a decrease in the mechanical properties (hardness and tensile strength) of TPE; however, it has been improved with the increased irradiation dose. The thermal analysis indicated that the addition of EPDM and high-energy electron beam crosslinking resulted in a new melting peak near $150^{\circ} \mathrm{C}$ in $\mathrm{TPE}$, and a new crystalline phase appears during the crystallization process. Repeated processing performance tests showed that the incorporation of higher PPB content reduces the loss of mechanical properties of the prepared blend. The micro-morphology of the cell structure in foamed TPE material was investigated, and it was found that the size of cell structure gradually decreased with the increased EPDM content; however, the cell size has a tendency to increase first and then decrease with the increase of irradiation dose. At $40 \mathrm{kGy}$ irradiation dose, the cell structure size is the largest among all EPDM/PPB foams. The cyclic compression test of the TPE foamed material showed that the material's resistance to repeated compression got promoted with the increased EPDM content.
\end{abstract}

Keywords: mechanical properties, microcellular foam, EPDM/PPB blend, supercritical $\mathrm{CO}_{2}$, electron beam irradiation

\section{Introduction}

The development of foam materials has been continuous over the past two decades, which reveals the importance of various foams due to their excellent performance, economical and practical application properties. The presence of foam cells in the polymer reduces the density of the material, which cuts down the total quantity of raw material to be used to make it cost-effective. Polymer foams prepared with different materials with intrinsic properties attracted a lot of attention in various applications such as furniture, transportation, appliances, sporting goods, padding etc. [1-4]. The use of foaming agents [5-7] has an importance in the polymer foam preparation process. Supercritical (sc) $\mathrm{CO}_{2}$ and $\mathrm{sc}-\mathrm{N}_{2}$ become the mainstream foaming agent, as they are environment friendly [8-10]. Saturation temperature, pressure, and time are important factors in regulating the permeability of sc-fluids to the polymers [1-14]. Hence sc-fluids are regulated easier in practice to achieve the desired penetration rate during the foaming process. However, it is necessary to look towards the safety of the processing equipment, which is a prerequisite for the actual production of polymer foams.

The cell structure of the polymer foam depends on the amount of sc-fluids penetrated into the polymer 
at a certain temperature and the rheological properties (viscosity and modulus) of the polymer at that certain temperature $[14,15]$. In fact, due to the characteristics of the polymer and the external force applied under actual condition of use, the cell structure may have various degrees of differences, such as cell breakage, merger, and collapse [16]. Radiation crosslinking based on the radical reaction principle is an effective method to improve the stiffness and viscosity of polymer chains, which improves the strength of the cell wall, and also, the irradiation dose (ID) can be adjusted to control the degree of crosslinking [1720]. The high flexibility of ID ultimately improves the dimensional stability of the polymeric foam. The irradiation crosslinking process also does not produce any by-product and no pollution to the polymer matrix; hence it is more advantageous than traditional chemical crosslinking methods $[21,22]$.

Blended foaming of rubber and plastic can improve the performance of the foamed material. Rubber can be used as a continuous phase and plastic as a dispersed phase to improve the strength of the foamed material, and vice-versa can be used to improve the toughness of the foamed material [23-27]. In general, the selection of the suitable two-phase blended material for foaming is a challenge, to achieve better performance characteristics of the foamed material, which can be used widely. At present many research groups have prepared and studied blending foaming with different rubber and plastic materials such as; EVA/NR/PP, NBR/CPVC, NBR/PLA, PP/waste ground rubber tire powder, etc. where they achieved improved microstructural results and physico-mechanical properties along with material recycling [28-31].

As an important product of rubber and plastic blending foaming, EPDM/PP thermoplastic elastomer prepared by dynamic vulcanization has excellent weather resistance, ozone resistance, UV resistance and high-temperature properties, electrical properties, impact resistance, oil and solvent resistance, which is equivalent to the general-purpose $\mathrm{CR}$ (chloroprene rubber) $[32,33]$. In addition, EPDM/PP can be processed without vulcanization as well as by standard thermoplastic processing equipment. It has an advantage of simple processing, continuous production, a cost-effective, recyclable material, which has often been used as a raw material for weather-strip seals in the automotive door system [34]. Many researchers worked on modification and foaming properties of EPDM/PP. Jolfaei et al. [35] reported PP/EPDM/organoclay (15 A) foam with improved mechanical properties, where they used two compatibilizers MA grafted with EPDM and PP. An increased content of organoclay allows decreasing of the EPDM droplet size to improve the dispersibility of organoclay. Xu et al. [36] studied a dynamically vulcanized PP/EPDM blends with balanced stiffness and toughness through the in-situ synthesis of zinc dimethacrylate (i-ZDMA), where the MAA/ZnO reaches $2 / 1.3$, the Izod impact strength increased to $80.1 \mathrm{~kJ} / \mathrm{m}^{2}$, Young's modulus and yield strength increased to 373 and $14.8 \mathrm{MPa}$ respectively, significantly improved the hardness of the PP/EPDM blend.

As a plastic, Propylene/1-butene (PPB) copolymer is a random copolymer of propylene and 1-butene, which has its unique advantages; 1-butene introduction in polypropylene (PP) segment can destroy the segment regularity, reduces the crystallinity of the material, at the same time reduces the polymer melting temperature, widens the melting temperature window and improves the processability of the material. In addition, the branched chains in the molecular structure of the PPB provide higher melt strength in comparison to PP. It is more difficult to prepare foam material with low melting strength; hence PPB is more favorable as a foaming material, which solves the short melting range issue over PP [37-39]. In practical use, PP becomes brittle in a low-temperature environment and causes self-damage [40], whereas PPB has a lower use temperature and has better rigidflexible balance. PPB material can be tuned by controlling the 1-butene content; hence the rigidity and flexibility can meet the requirement of use in a different stress environment. However, as per research studies and to the best of our knowledge, there is almost no available literature about the foaming of PP/1-butene copolymers. As a buffer energy-absorbing material, it is necessary to toughen the PPB material. It is envisaged that EPDM and PPB are melt blended, where EPDM is used as a rubber phase, and PPB is used as a plastic phase to obtain a new type of thermoplastic elastomer (TPE) material. Due to the superior properties of $\mathrm{PPB}$ as compared to $\mathrm{PP}$ and excellent compatibility between PPB and EPDM, this new TPE material with better performance can possibly replace the traditional EPDM/PP material.

In this article, we report the foaming of EPDM/PPB using sc- $\mathrm{CO}_{2}$. EPDM rubber is mixed with $\mathrm{PPB}$ in an internal mixer and after compression molded, then 
it is subjected to radiation pre-crosslinking treatment to prepare TPE for sc- $\mathrm{CO}_{2}$ distribution and foaming. The effect of EPDM content and irradiation dose (ID) on the repetitive processing properties and mechanical properties of foamed EPDM/PPB blends and cell morphology and reciprocating compression properties of EPDM/PPB foams were well studied and correlated. The developed EPDM/PPB foam with good mechanical performance and buffer energy-absorbing properties can be a potential replacement to the currently available foam material.

\section{Experimental}

\subsection{Materials}

The PPB with 18\% 1-butene content, was obtained from Shandong Dongfanghongye Chemical Co., Ltd, China; EPDM (code number S512F) was offered by SK Co. $\mathrm{CO}_{2}$ with a purity above $99.8 \%$ was used, commercially available; Xylene solvent, analytically pure, was offered by Sinopharm Chemical Reagent Co., Ltd, China.

\subsection{Sample preparation}

A complete process of Foam material preparation has been shown in a schematic diagram in Figure 1. The material compositions and parameters used to prepare the samples are listed in Table 1. The operation sequence of this experiment, includes two steps: The first step is to prepare blends with different EPDM/PPB content ratios (0/100, 20/80, 40/60, $50 / 50,60 / 40)$. All the materials with different component contents were blended in an internal mixer (Shanghai Kechuang co., Ltd, XSS-300, China) with a rotor speed of $50 \mathrm{rpm}$ at $180^{\circ} \mathrm{C}$ for $5 \mathrm{~min}$ (after the torque curve is stable), the resulting melt was directly placed into a molding machine (Qingdao Yadong
Table 1. Different EPDM and PPB contents and irradiation doses.

\begin{tabular}{|c|c|c|}
\hline $\begin{array}{c}\text { PPB content } \\
{[\mathbf{w t} \% \mathbf{]}}\end{array}$ & $\begin{array}{c}\text { EPDM content } \\
{[\mathbf{w t} \% \mathbf{]}}\end{array}$ & $\begin{array}{c}\text { Irradiation dose } \\
{[\mathbf{k G y}]}\end{array}$ \\
\hline 100 & 0 & $0,20,40,70$ \\
\hline 80 & 20 & $0,20,40,70$ \\
\hline 60 & 40 & $0,20,40,70$ \\
\hline 50 & 50 & $0,20,40,70$ \\
\hline 40 & 60 & $0,20,40,70$ \\
\hline
\end{tabular}

Rubber Machinery co. Ltd, XLB, China) to be pressed into a $2 \mathrm{~mm}$-thick sheet and $4 \mathrm{~mm}$-thick sheet respectively. The second step is to pre-crosslink all the blends sheets through a high-energy electron beam irradiation at various dosages $(0,20,40,70 \mathrm{kGy})$.

\subsection{Foam preparation}

Post-irradiation EPDM/PPB blend sheets were expanded through one-step foaming technology in the overall lab-scale autoclave system. Plate samples $(2 \times 3 \times 12 \mathrm{~mm})$ were enclosed into a high-pressure vessel. The vessel was flushed with low-pressure $\mathrm{CO}_{2}$ for $3 \mathrm{~min}$ and preheated to $138^{\circ} \mathrm{C}$. Afterward, the pressure was increased to a saturation pressure of $15 \mathrm{MPa}$ by a high-pressure pump and maintained at this pressure for $2 \mathrm{~h}$. After saturation, the pressure was quenched to atmospheric pressure within $3 \mathrm{~s}$, and the samples were taken out. Then foam structure was allowed to full growth during rapid depressurization with the depressurization rate of $5 \mathrm{MPa} / \mathrm{s}$.

\section{Characterization}

\subsection{Physical, mechanical performance testing}

The Shore D hardness tests were carried out according to ISO 7619-1 using a hardness tester Shore Zwick Hardness Testers. This method is based on a penetration test of a penetrator and requires relatively

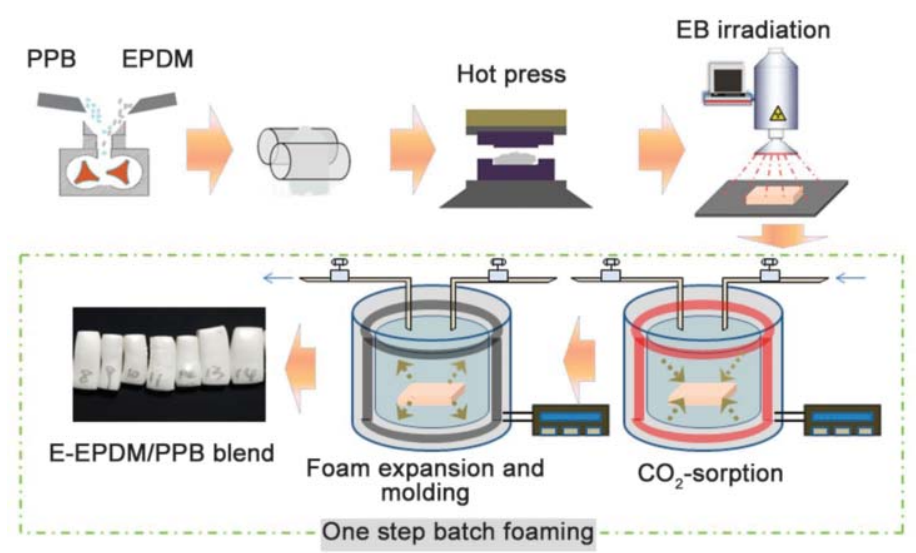

Figure 1. Schematic of the material preparation process. 
thick samples. Five readings of hardness at different positions were taken, and the average value was calculated.

Tensile strength tests of the post-irradiation EPDM/ PP blends sheets were performed on specimens of $4 \mathrm{~mm}$ width and $2 \mathrm{~mm}$ thickness at $23^{\circ} \mathrm{C}$ according to ASTM D-638 at a cross-head speed of $20 \mathrm{~mm} / \mathrm{min}$. The average value of 5 times of tensile strength for each sample has been considered for the result.

\subsection{Foaming properties}

The Volume Expansion Ratio (VER) of various EPDM/PPB foaming samples was calculated by Equation (1) [41]:

$\theta=\frac{\rho_{\mathrm{f}}}{\rho_{\mathrm{p}}}$

where $\theta, \rho_{\mathrm{f}}$ and $\rho_{\mathrm{p}}$ are the VER, bulk densities of the pre-foam, and post-foam samples, respectively. The $\rho_{\mathrm{f}}$ and $\rho_{\mathrm{p}}$ values were measured by the water displacement method according to ISO 1183-1987.

In this investigation, the cell size was analyzed using an image analysis tool (Image-pro-plus), the cell density in a unit volume $(N)$ is calculated by Equation (2) [41]:

$$
N=\left(\frac{n}{A}\right)^{\frac{3}{2}} \cdot \theta
$$

The $n$ in Equation (2) is the cell number observed in the optical microscope. Furthermore, $A$ is the image area obtained in the microscope.

The energy absorption capacity of the material can be characterized by the amount of energy absorbed by the unit volume of material. The graphic area under by the compression stress-strain curve and the coordinate axis is absorbed energy by the unit volume of material, can be calculated from Equation (3):

$$
\omega=\int_{0}^{\varepsilon} \sigma \mathrm{d} \varepsilon
$$

where $\omega$ represents the energy absorption capacity per unit volume of the material, $\sigma$ represents the internal stress of the material under compression, $\varepsilon$ represents the strain generated by the material under compression.

\subsection{DSC measurement}

The melting behavior of EPDM/PPB blends sheets after each post-irradiation/non-irradiation cycle was determined using a differential scanning calorimeter of type (DSC204F1, NETZSCH) calibrated with indium. During the DSC tests, a thermal scanning from 30 to $200^{\circ} \mathrm{C}$ with a heating rate of $10^{\circ} \mathrm{C} / \mathrm{min}$ was applied.

\subsection{Repeated processing performance testing}

The post-irradiation blends sheets with different EPDM mass fractions with an irradiation dose of $70 \mathrm{kGy}$ were divided into 5 groups. A torque rheometer was used for the repeated processing experiments. The processing temperature was $180^{\circ} \mathrm{C}$, the rotor speed was $50 \mathrm{rpm}$, and each processing lasted $5 \mathrm{~min}$. Then, the plate vulcanizer was used to press the blends with different processing times to $2 \mathrm{~mm}$ samples, we cut them into standard tensile test samples, and tested the tensile properties, to study the effects of different processing times on the mechanical properties of the prepared materials.

\subsection{Microstructural testing \\ 3.5.1. EPDM/PPB blends compatibility}

A scanning electron microscope (SEM) with an acceleration voltage of $5 \mathrm{kV}$ (JEOL, JSM-7500F, Japan) used to study the surface morphology of the material. All samples were cryo-fractured by immersing in liquid nitrogen; the EPDM components on the brittle section of the sample were etched with xylene at room temperature. The obtained fracture surfaces were coated with a thin layer of gold by a sputtering unit before further observations.

\subsubsection{The morphology of EPDM/PPB blends after repeated processing}

Same as 3.5.1, SEM was used to observe the microstructure of the EPDM/PPB foam pores in the brittle section of the sample after repeated processing, but we did not need to use xylene reagent to etch the EPDM components on the brittle surface. A comparative analysis was made.

\subsubsection{Foam characterization of EPDM/PPB blends}

Same as 3.5.1, SEM was used to observe the microstructure of the foam pores in the brittle section of the sample after foaming, but we did not need to use xylene reagent to etch the EPDM components on the brittle surface. A comparative analysis was made.

The density of the foams was measured as ASTM D792 using an electronic density meter. 


\subsection{Hysteresis loss testing of EPDM/PPB foam}

To estimate the potential cushioning and recovering capacities of the prepared foam, loading, and unloading curves were obtained. The hysteresis loss performance of foaming materials was tested according to standard GB/t33609-2017. Samples of foaming materials with similar density were selected. In this experiment, EPDM/PPB foaming samples with different EPDM mass fraction and density of $0.06 \mathrm{~g} / \mathrm{cm}^{3}$ and irradiation dose of $20 \mathrm{kGy}$ were used. The samples were cut into standard samples with a size of $50 \mathrm{~mm} \times 50 \mathrm{~mm} \times 25 \mathrm{~mm}$, and the samples were placed on the universal testing machine for the mechanical study. Each sample was pre-pressed twice at the loading and unloading rates of $200 \mathrm{~mm} / \mathrm{min}$ and then compressed for 5 times at the loading and unloading rates of $50 \mathrm{~mm} / \mathrm{min}$. The sample data were recorded and then sorted into images for analysis and comparison study.

\section{Results and discussion}

\subsection{EPDM/PPB material compatibility analysis}

Figure 2 is a comparison diagram of the microstructure of the brittle section after solvent etching of EPDM/PPB materials with different blending ratios and different irradiation doses. From top to bottom, the irradiation dose of each column increased successively as $0 \mathrm{kGy}$ (non-irradiated), 40, and $70 \mathrm{kGy}$. From left to right, the content of EPDM in EPDM/ PPB materials increased successively from $0 \mathrm{wt} \%$ (pure PPB), 20, 40, 50 to $60 \mathrm{wt} \%$. It has been observed that the compatibility of PPB and EPDM in EPDM/PPB material is very good, and the dispersion of the micron-scale can be achieved only through simple melting blending. It can be seen from the cross-section of the non-irradiated blend that when the EPDM content is $20 \mathrm{wt} \%$, the dispersed phase EPDM and the matrix phase PPB are distributed in a 'sea-island' structure, and EPDM is distributed in the continuous phase PPB as an 'island phase' with a size of about $1 \sim 5 \mathrm{~nm}$. With the increase of EPDM content, the dispersed island phases were gradually connected with each other, which was shown in the SEM images as a 'tunnel' structure with a diameter of about $1 \sim 5 \mu \mathrm{m}$ that was connected with each other in the matrix phase. When the content of EPDM increased to $60 \mathrm{wt} \%$, the 'tunnel' like structures in the SEM images were interconnected, and the blend material finally formed a co-continuous phase structure. With the increase of irradiation dose, the crosslinking degree of EPDM components increases, and more crosslinking networks are formed between molecules. The crosslinked EPDM components can only swell and cannot be dissolved. When the irradiation
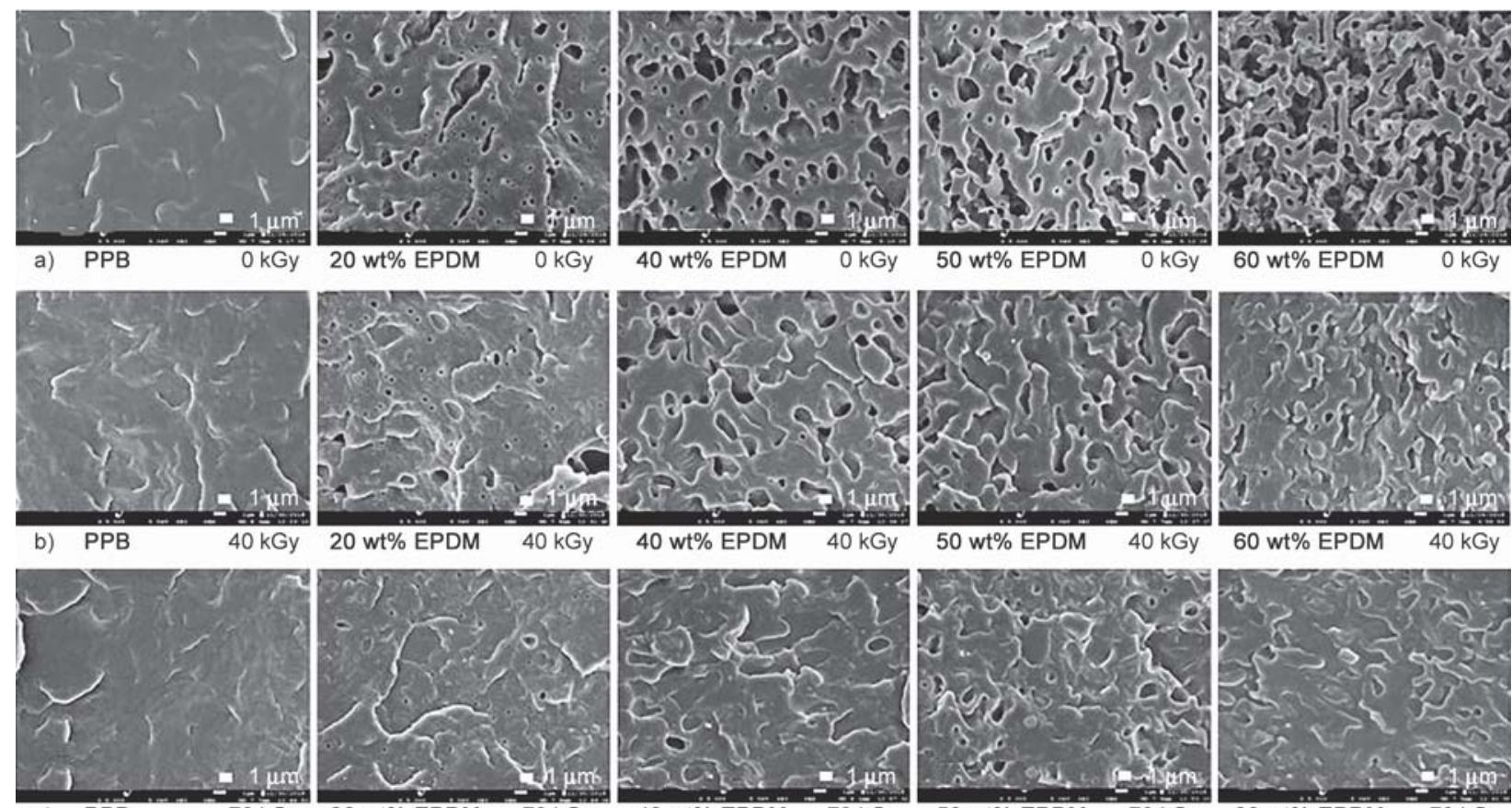

Figure 2. SEM images showing the two-phase structure of TPE with different EPDM content at different irradiation doses. All SEM images have the same scale bar, i.e. $1 \mu \mathrm{m}$. (a) $0 \mathrm{kGy}$, (b) $40 \mathrm{kGy}$ and (c) $70 \mathrm{kGy}$. 
dose was $40 \mathrm{kGy}$, the crosslinking degree was relatively low, and part of the non-crosslinked EPDM could still be dissolved in xylene. Therefore, a small number of holes could be observed in the etched section of the SEM images with low EPDM content, while the concave-convex continuous structure could be observed in the etched section SEM images with high EPDM content. When the radiation dose increased to $70 \mathrm{kGy}$, most EPDM components were crosslinked, and no EPDM components could be dissolved in xylene. Therefore, it was difficult to observe the pore structure in the etched section electron microscopy with low EPDM content, and the concave-convex continuous structure in the etched section electron microscopy with high EPDM content became smoother.

\subsection{Mechanical properties of EPDM/PPB materials}

Figure 3 and Figure 4 show the hardness and tensile strength of EPDM/PPB materials with different EPDM contents and irradiation doses. With the increase of EPDM content, both the hardness and tensile strength of EPDM/PPB foam material showed a decreasing trend. This could be ascribed to the excellent molecular chain mobility of the EPDM phase, as an elastic rubber dispersed in the PPB plastic phase. It can play a toughening role and reduce the crystallinity of the PPB plastic, thereby lowering the brittleness and the Shore D hardness of the PPB material. Compared to pure PPB, the decrement in the tensile strength of the EPDM/PPB blends is caused by EDPM which reduces the crystallinity of PPB, and destroys the three-dimensional ordered structure of the crystal.

However, with the increase of irradiation dose, the tensile strength and hardness of EPDM/PPB material with various blend ratios should increase, and a more significant enhancement effect of irradiation on the tensile strength and hardness of samples has been observed at the higher EPDM content. This is due to the fact that the irradiation crosslinks the molecular chains into a crosslinked network structure, which increases the molecular weight of the material. The higher the irradiation dose, the more obvious the crosslinking effect of the irradiation on the material, which means the higher the irradiation dose, the greater the crosslinking degree of the material. Compared with PPB, the components of EPDM contain unsaturated groups, which are more likely to break

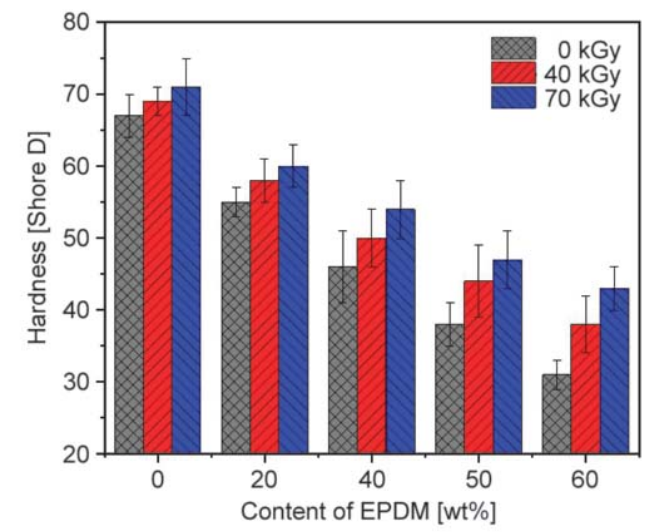

Figure 3. Shore D hardness of TPE with different content of EPDM at different irradiation doses.

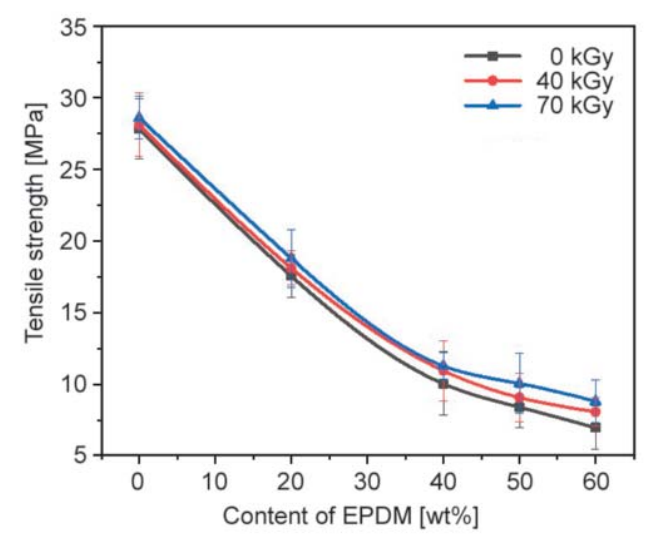

Figure 4. Tensile strength of TPE with different EPDM content at different irradiation doses.

under the action of a high-energy electron beam to regenerate new crosslinking bonds. Irradiation crosslinking improved the mechanical properties of EPDM/PPB materials with high EPDM content. The foaming process of EPDM/PPB materials is a completely physical process, which does not involve the breaking and formation of chemical bonds. Therefore, the mechanical properties of EPDM/PPB materials with different blending ratios and different irradiation doses also reflect the trend of mechanical properties changes after supercritical foaming.

\subsection{Thermal analysis}

Figure 5 shows the DSC curves recorded during the heating process of three groups of EPDM/PPB materials with different blending ratios of non-irradiated (Figure 5a) and irradiated doses of $40 \mathrm{kGy}$ (Figure 5b) and $70 \mathrm{kGy}$ (Figure 5c). DSC curves of EPDM/PPB materials at different irradiation doses all change with the change of EPDM content and exhibit the same trend. The melting peak area of EPDM/PPB heating section gradually decreases with the increased 
EPDM component content, which is attributed to the decrease of plastic phase content and the corresponding decrease of crystal region proportion. While comparing the DSC curves of three groups of PPB materials with different irradiation doses, we observed that a new melting peak appears at the melting
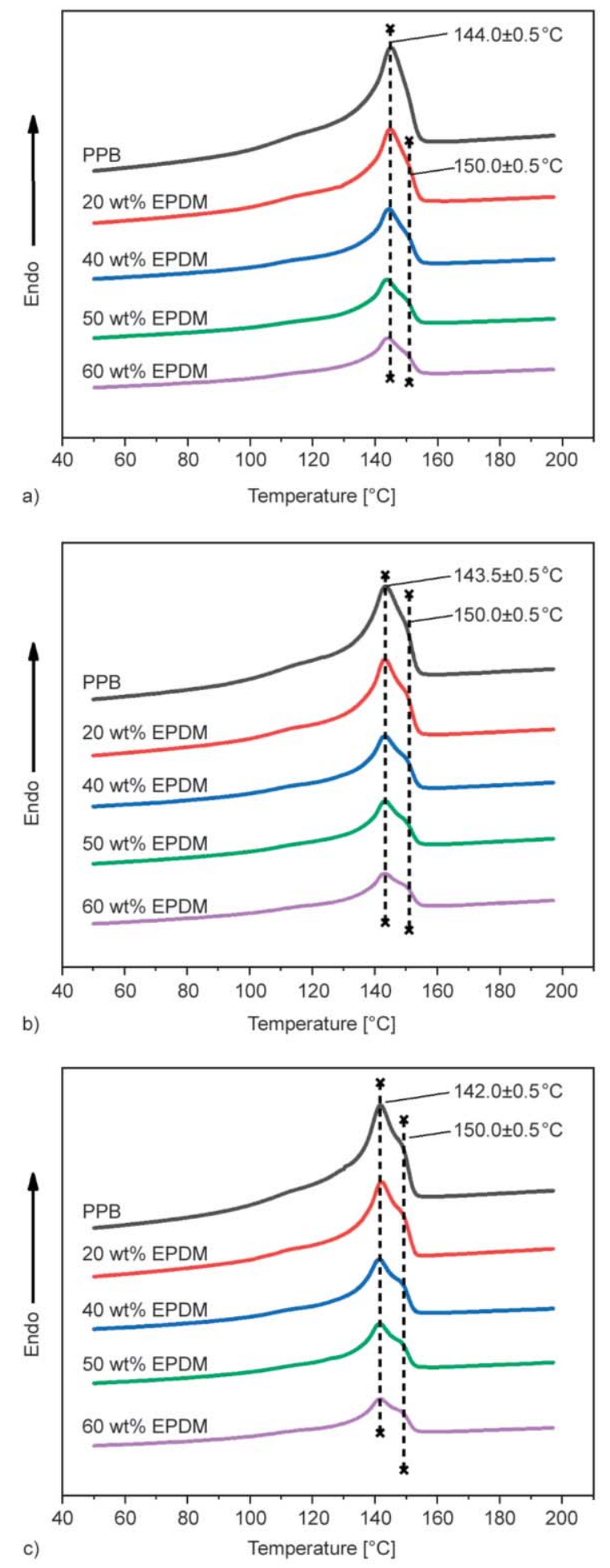

Figure 5. DSC thermograms (heating process) of TPE with different EPDM content at different irradiation dose, (a) 0 kGy, (b) $40 \mathrm{kGy}$, and (c) $70 \mathrm{kGy}$. temperature near $150^{\circ} \mathrm{C}$ of the irradiated crosslinked EPDM/PPB material (see Figure 5b, 5c), and the intensity of this peak is weaker than the melting peak of PPB. The higher the irradiation dose, the higher the intensity of the peak, and becomes more obvious in the curve, indicating that crosslinking caused a change in crystal form in the PPB material, and a new crystal form appeared during the crystallization process [42-43].

The DSC curves (see Figure 5a) of non-irradiated EPDM/PPB materials with different EPDM contents show that as the EPDM content increases, a melting peak will also appear in the same position near $150^{\circ} \mathrm{C}$, this peak being melting peak of the crystal region in EPDM. These results are in agreement with the findings of Kim et al. [44] and Bagheri et al. [45] showing that similar segments of molecular chain, being localized at the interface between the matrix and dispersed phase, functions as a compatibilizer and generated new beta-form crystals, and this might be the reason for the secondary melting behavior of pure PPB on the DSC curve after various irradiation dose [46]. The crystalline form has changed during the crystallization process and has become the same structural unit as the crystalline form of the crystal region in EPDM.

\subsection{Repeat processing performance of EPDM/PPB material}

Table 2 expresses the repeated processing performance test results of five EPDM/PPB materials with different EPDM content at $70 \mathrm{kGy}$ irradiation doses. Figure 6 shows the mechanical property loss of EPDM/PPB materials with different EPDM contents after repeated processing (calculated data are shown in Table 2). The higher the EPDM content, the lower the tensile strength of EPDM/PPB material. After five times of processing, pure PPB material can still maintain high tensile properties. However, the higher the EPDM component content of the EPDM/PPB material, the more tensile strength will be lost after multiple processing, and the more significant the mechanical property decline. This is because irradiation crosslinking has an effect on both PPB and EPDM components, but as EPDM components contain unsaturated groups, which are more sensitive to irradiation and are more prone to fracture and re-generation of linkage bonds between chain segments, irradiation mainly affects EPDM components and causes them to crosslink. When irradiated materials 
Table 2. The relationship between tensile strength and the number of processing times.

\begin{tabular}{|c|c|c|c|c|c|}
\hline $\begin{array}{c}\text { No. processing } \\
\text { times }\end{array}$ & $\begin{array}{c}\text { PPB } \\
{[\mathbf{M P a}]}\end{array}$ & $\begin{array}{c}\mathbf{2 0} \mathbf{w t} \% \mathbf{E P D M} \\
{[\mathbf{M P a}]}\end{array}$ & $\begin{array}{c}\mathbf{4 0} \mathbf{w t} \mathbf{\text { EPDM}} \\
{[\mathbf{M P a}]}\end{array}$ & $\begin{array}{c}\mathbf{5 0} \mathbf{w t} \mathbf{\text { EPDM}} \\
{[\mathbf{M P a}]}\end{array}$ & $\begin{array}{c}\mathbf{6 0} \mathbf{w t} \% \mathbf{E P D M} \\
{[\mathbf{M P a}]}\end{array}$ \\
\hline 1 & 32.51 & 19.37 & 11.41 & 10.7 & 8.99 \\
\hline 2 & 32.46 & 18.79 & 11.16 & 10.2 & 8.19 \\
\hline 3 & 32.36 & 18.39 & 10.89 & 9.96 & 7.78 \\
\hline 4 & 32.11 & 18.28 & 10.5 & 9.83 & 7.44 \\
\hline 5 & 31.92 & 17.99 & 10.25 & 9.47 & 6.71 \\
\hline
\end{tabular}

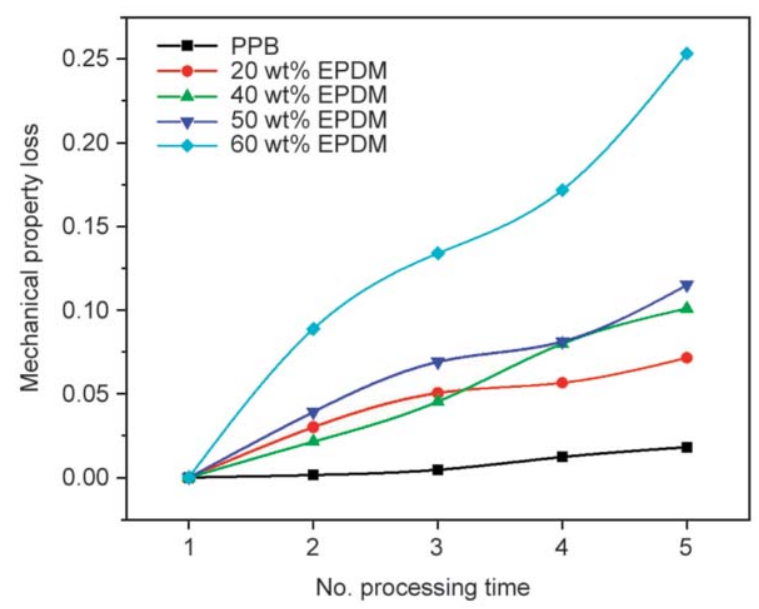

Figure 6. Multiple-processing performance TPE with different EPDM content.

are recycled and then extruded for hot processing, the crosslinked network structure in EPDM will break under the action of shear force, resulting in the reduction of molecular weight and mechanical properties of the materials. Therefore, the sensitivity of the mechanical properties of the material to the processing times is higher in EPDM/PPB material with higher EPDM contents. Hence, as the plastic phase in EPDM/PPB materials, the PPB component can provide good processing performance for $\mathrm{EPDM} / \mathrm{PPB}$ foam materials.

\subsection{Foam structure and characterization}

Figure 7. is a comparison of the cellular morphology, and average cell size of brittle sections of various EPDM/PPB foamed materials with different irradiation doses and different EPDM contents prepared under identical foaming conditions (at a temperature of $138^{\circ} \mathrm{C}$ with $15 \mathrm{MPa}$ saturation pressure for the period of $2 \mathrm{~h}$ ). Among them, from top to bottom, the irradiation dose of each column is 0 kGy (non-irradiated), 20, 40, and $70 \mathrm{kGy}$, which are sequentially increased. From left to right, EPDM content is $0 \%$ (pure PPB), 20, 40, 50, and 60\%, which increase in order, the size of the cell structure gradually decreases with the increase of EPDM content and with the increase of the irradiation dose. The EPDM/PPB foam with an irradiation dose of $40 \mathrm{kGy}$, where the size of the cell structure of the material is the largest among the irradiation doses of EPDM/PPB foam, clarifies that an appropriate irradiation degree is beneficial to the foaming of the EPDM/PPB material. The cell size of the EPDM/PPB foamed material without irradiation decreases with the content of EPDM component, mainly because the excessive addition of EPDM will significantly reduce the foaming temperature and the actual higher temperature will cause a gas overflow. When the irradiation dose is $40 \mathrm{kGy}$, the degree of crosslinking of the EPDM component is appropriate, the melt strength of the material is improved to a certain degree, and more gas can be held during the foaming process. Therefore, the EPDM/PPB foam at this irradiation dose can be made larger and from Figure 8 . we can clearly see that the large cell size distribution became wider, and their small cell size distribution changed slightly. With the increase of the irradiation dose, the degree of crosslinking of the EPDM component increases significantly, the melt strength becomes too high during the foaming process, the polymer fluidity decreases, and the resistance to bubble growth increases, so the structure of the prepared cell is relatively small, and the VER (volume expansion ratio) of the foam is low. When the EPDM content is $60 \%$, and the irradiation dose reaches $70 \mathrm{kGy}$, EPDM forms a continuous phase in the EPDM/PPB blends and has a very high degree of crosslinking, in this case, the cell growth becomes extremely difficult, so no pores are generated.

Figure 8 is the cell size distribution and cell density of the sample obtained by EPDM/PPB blend under different processes and formulations, which gives a detailed description of EPDM and high-energy electron beam irradiation technology together with its role played in it. It could be noted from Figure 8a, $8 \mathrm{~b}, 8 \mathrm{c}$ that as the EPDM content increases (without high-energy electron beam irradiation), the cell size 

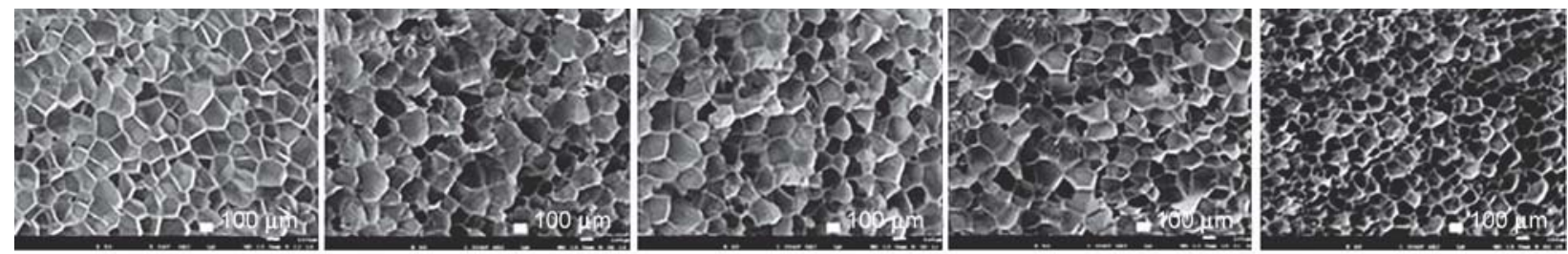

a) PPB

0 kGy 20 wt\% EPDM

0 kGy 40 wt\% EPDM

0 kGy 50 wt\% EPDM

$0 \mathrm{kGy}$

$D=145.0 \pm 12 \mu \mathrm{m}$

0 kGy $D=176.7 \pm 13 \mu \mathrm{m}$
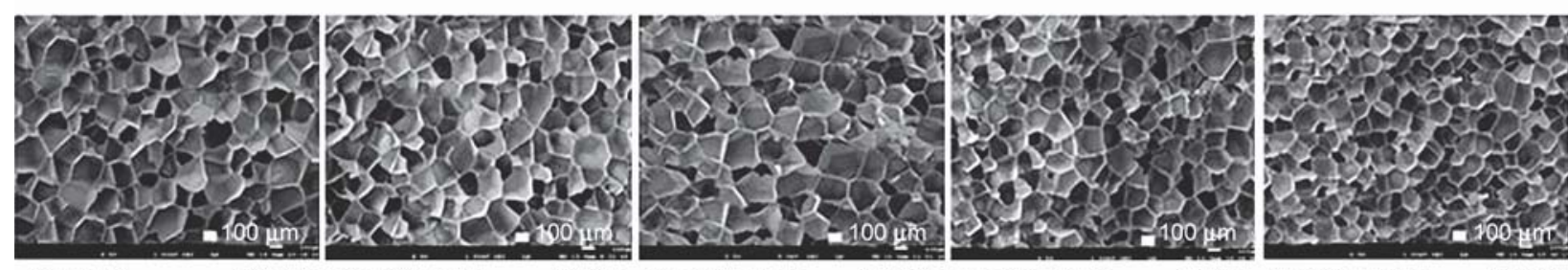

b) PPB r $\begin{array}{r}20 \mathrm{kGy} \\ D=191.9 \pm 11 \mu \mathrm{m}\end{array}$

$20 \mathrm{wt} \%$ EPDM $20 \mathrm{kGy}$
$D=185.3 \pm 9 \mu \mathrm{m}$

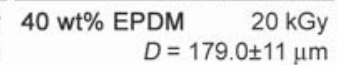

$50 w t \%$ EPDM 20 kGy
$D=155.4 \pm 15 \mu \mathrm{m}$

60 wt\% EPDM 20 kGy
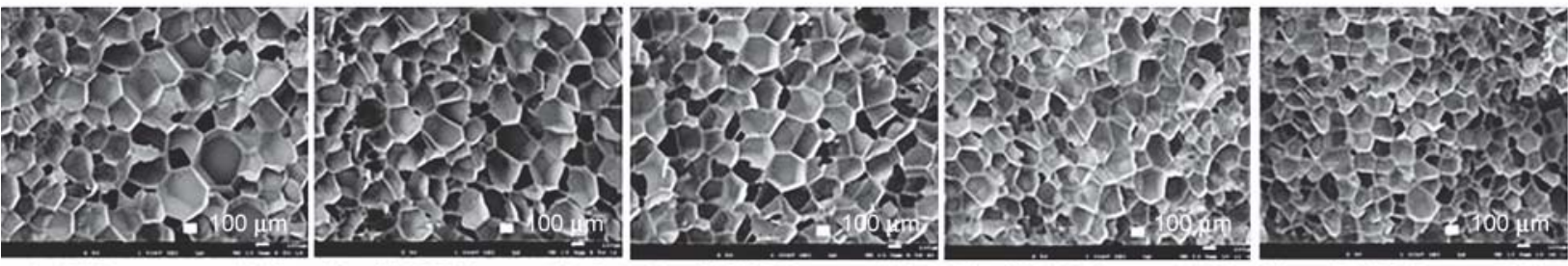

c) PPB $D=192.9 \pm 11 \mu \mathrm{m}$

$D=198.8 \pm 15 \mu \mathrm{m}$

$D=207.9 \pm 11 \mu \mathrm{m}$

$D=185.7 \pm 18 \mu \mathrm{m}$

$D=171.1 \pm 10 \mu \mathrm{m}$
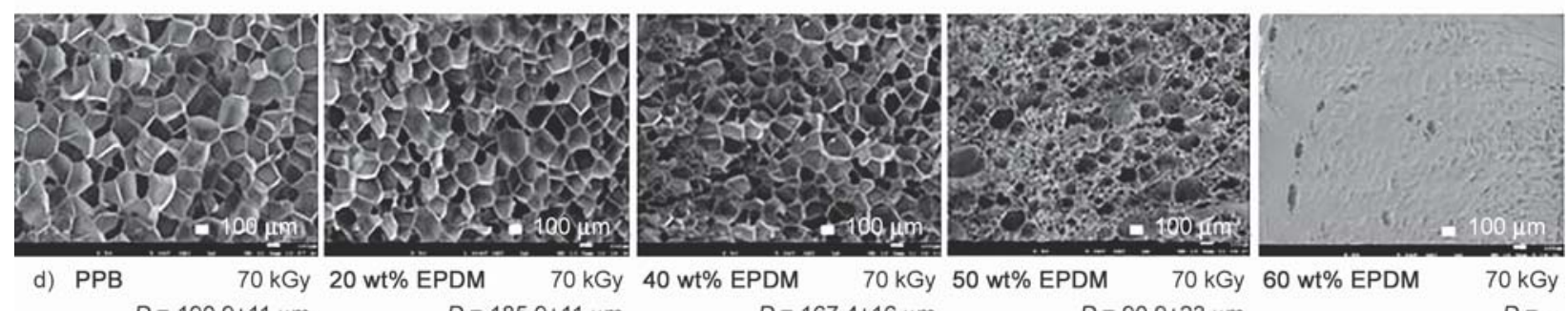

$D=185.9 \pm 11 \mu \mathrm{m}$

$D=167.4 \pm 16 \mu \mathrm{m}$

$D=90.9 \pm 23 \mu \mathrm{m}$

$60 \mathrm{wt} \%$ EPDM $\quad 70 \mathrm{kGy}$ $D=190.9 \pm 11 \mu \mathrm{m}$

Figure 7. SEM images showing cell structure of TPE foam with different EPDM content at different irradiation dose, the corresponding average cell density is analyzed. (Scale bar for all images are of the same size, i.e. $100 \mu \mathrm{m}$ ). (a) $0 \mathrm{kGy}$, (b) $20 \mathrm{kGy}$, (c) $20 \mathrm{kGy}$ and (d) $70 \mathrm{kGy}$.

distribution range becomes wider, changed from original $80 \sim 260$ to $60 \sim 280 \mu \mathrm{m}$, corresponding the cell densities changed from $1.9 \cdot 10^{6}$ to $1.0 \cdot 10^{6} \mathrm{cell} / \mathrm{cm}^{3}$. From the height of the histogram, it can be seen that the cell size changes from the original relative concentration to cell sizes distribution inhomogeneously. This should be ascribed to the increment in the number of EPDM content, which results in different foaming processes in the EPDM and PPB phases under identical experimental conditions and in the different stages of cell nucleation and growth. In addition, the increment in the number of EPDM content will increase the area of the interface between the two phases, resulting in heterophasic nucleation (low nucleation energy), which gives priority to foaming. In Figure 8c, 8d and 8e, with the increment dose of irradiation, the cell size distribution range becomes narrow; clearly, the apparent density of the material at the same component content drops significantly, correspondingly the cell formation in EPDM/PPB blend foams became (as shown by Figure 7), which is due to the appropriate crosslinking strength in EPDM/PPB blends.

The effect of irradiation dose and EPDM content on the VER of EPDM/PPB blend foam is shown in Figure 9. If the irradiation dose is $0 \mathrm{kGy}$, as the EPDM increases to $60 \mathrm{wt} \%$, the VER of foam decreases rapidly. The gas easily escapes from the EPDM and EPDM/PPB interface, which decreases the foaming expansion ratio. The VER of 40 and 70 kGy materials increases first and then decreases with inceasing irradiation dose. A three-dimensional network structure is formed, which increases the melt strength and much more gas can be locked in the cell, hence 

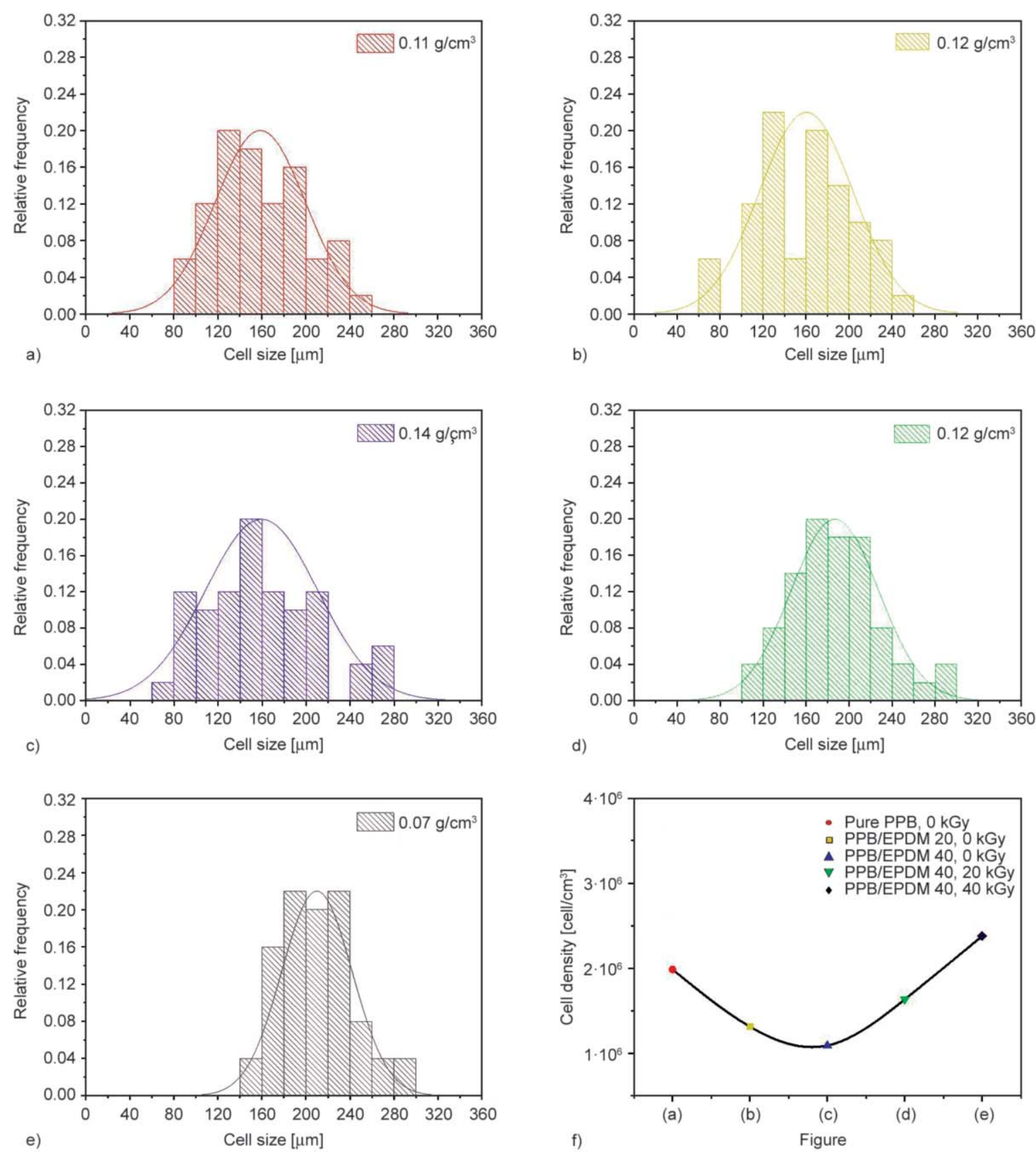

Figure 8. Cell size distribution of PPB/EPDM blending foams: (a) Pure PPB with no irradiation dose; (b) PPB/EPDM 20 with no irradiation dose; (c) PPB/EPDM 40 with no irradiation dose; (d) PPB/EPDM 40 with 20 kGy irradiation dose; (e) PPB/EPDM 40 with 40 kGy irradiation dose; and (f) cell density of above different foams.

improves the VER of foam, but the further increase in irradiation dose will cause the decrement in VER of foam, mainly because EPDM crosslinks form a strong three-dimensional network structure, the elasticity is significantly increased, and cell growth becomes difficult.

\subsection{Hysteresis loss of EPDM/PPB foam}

Figure 10 shows the hysteresis loss test results for EPDM/PPB foamed materials with a density of about $0.11 \mathrm{~g} / \mathrm{cm}^{3}$ at an irradiation dose of $20 \mathrm{kGy}$ with different EPDM contents. Under the same test conditions, pure PPB foaming material has very slow recovery from compression deformation and does not have resistance to repeated compression. Here, only the hysteresis loss characteristics of EPDM/PPB foaming materials with EPDM contents of 20, 40, 50 , and $60 \%$ with similar densities are analyzed. The stress-strain curve of the cyclic loading and unloading process forms a hysteresis loop. The area of the hysteresis loop represents the loss of energy in one cycle per unit volume of foaming material under 


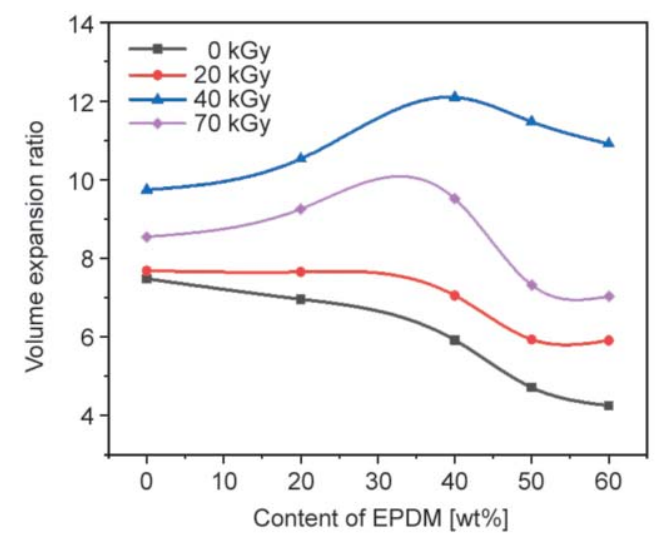

Figure 9. The variation of volume expansion ratio of EPDM/PPB foam with varied EPDM content and irradiation doses. compression. As the number of loading and unloading times increases, the area of the hysteresis loop gradually decreases, and the effect of energy absorption and energy loss gradually decreases. The four EPDM/PPB foaming materials with EPDM content are all compressed to $75 \%$ of the strain. The maximum value of compressive stress decreases with the increase of EPDM component content, from a maximum of 0.15 to $0.06 \mathrm{MPa}$, correspondingly. The area of the hysteresis loop also gradually decreases.

Table 3 shows the statistical results calculated by formula according to the cyclic compression stress-strain curves of four foams. The energy loss of each compression is calculated from the area of

Table 3. Result of circulating compression test.

\begin{tabular}{|c|ll|r|r|r|r|r|}
\hline EPDM content & \multicolumn{2}{|c|}{ Cycles } & $\mathbf{1}$ & $\mathbf{2}$ & $\mathbf{3}$ & \multicolumn{1}{c|}{$\mathbf{4}$} & \multicolumn{1}{c|}{$\mathbf{5}$} \\
\hline \multirow{2}{*}{$20 \mathrm{wt} \%$} & Energy loss & {$[\mathrm{kJ}]$} & 3.09 & 1.49 & 1.28 & 1.19 & 1.12 \\
\cline { 2 - 9 } & Lag factor & {$[\%]$} & 61.21 & 44.31 & 41.23 & 39.74 & 38.76 \\
\hline \multirow{2}{*}{$40 \mathrm{wt} \%$} & Energy loss & {$[\mathrm{kJ}]$} & 1.67 & 0.84 & 0.73 & 0.68 & 0.64 \\
\cline { 2 - 9 } & Lag factor & {$[\%]$} & 51.13 & 35.29 & 32.54 & 31.17 & 30.27 \\
\hline \multirow{2}{*}{$50 \mathrm{wt} \%$} & Energy loss $[[\mathrm{kJ}]$ & 1.04 & 0.56 & 0.49 & 0.45 & 0.43 \\
\cline { 2 - 9 } & Lag factor $[\%]]$ & 39.93 & 26.85 & 24.61 & 23.48 & 22.74 \\
\hline \multirow{2}{*}{$60 \mathrm{wt} \%$} & Energy loss $[\mathrm{kJ}]$ & 0.49 & 0.26 & 0.23 & 0.21 & 0.20 \\
\cline { 2 - 9 } & Lag factor $[\%]$ & 28.30 & 17.92 & 16.36 & 15.48 & 14.87 \\
\hline
\end{tabular}
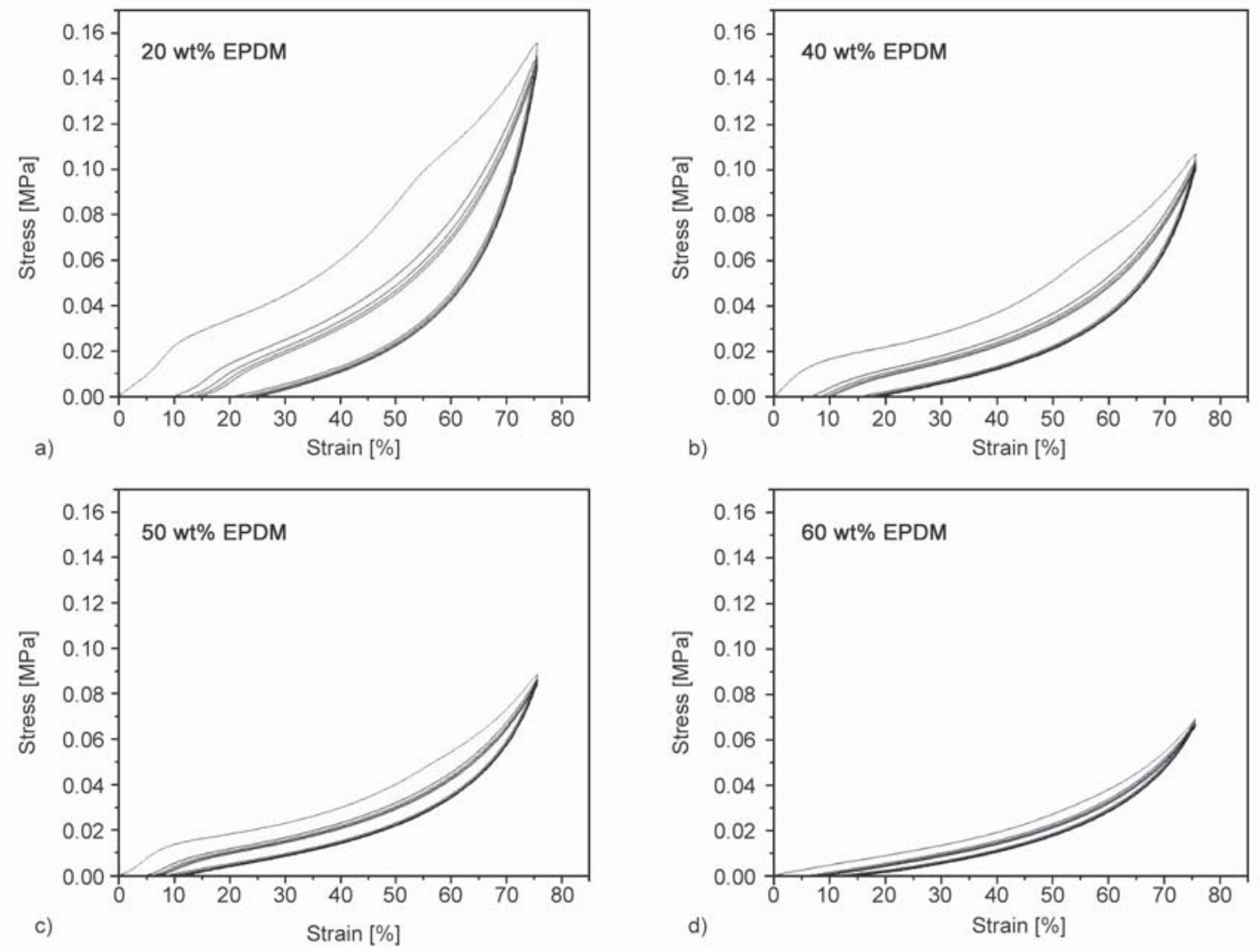

Figure 10. Circulating compression test of TPE with different EPDM content. (a) $20 \mathrm{wt} \%$, (b) $40 \mathrm{wt} \%$, (c) $50 \mathrm{wt} \%$ and (d) $60 \mathrm{wt} \%$. 
the hysteresis curve, and the energy absorption loss of each material decreases with the increase of compression times (see Table 3). The highest compression energy loss occurs in 5 cycles for EPDM/PPB foaming materials with EPDM content of $20 \%$, and the lowest compression energy loss occurs in 5 cycles for EPDM/PPB foaming materials with EPDM content of $60 \%$. This indicates that the energy-absorption effect of EPDM/PPB foaming materials with a high content of plastic phase is better in the compression process, so the shock absorption and energy absorption characteristics in the compression process of EPDM/PPB foaming materials are provided by the plastic phase in EPDM/PPB material. Due to this reason, TPE foams material with EPDM/PPB: $60 / 40$, will be the best foam for the application of buffer energy-absorbing.

With the increase of EPDM content in EPDM/PPB foaming material and the formula to calculate the hysteresis factor, the rate of change of smaller hysteresis factors of EPDM/PPB foaming materials (different EPDM content) has been observed. The rate of change of a hysteresis factor of EPDM/PPB foaming material (20\% EPDM content) with 5 times (cycles) of compression hysteresis factor gradually reduced from 61.21 to $38.76 \%$. Before and after compression, the observed change is $22.45 \%$, which is the largest change in several kinds of material. The hysteresis factor of EPDM/PPB foaming materials with $40 \%$ EPDM content decreased from 51.13 to $30.27 \%$, a change of $20.86 \%$. The hysteresis factor of EPDM/PPB foaming materials, with 50\% EPDM content, decreased from 39.93 to $22.74 \%$, with a change of $17.19 \%$. The hysteresis factor of EPDM/ PPB foaming materials with $60 \%$ EPDM content decreased from 28.30 to $14.87 \%$, with a change of $13.43 \%$, which was the least among the materials. The above results indicate that the higher the content of EPDM component in EPDM/PPB foaming material (EPDM/PPB: 60/40), the smaller the hysteresis factor, and the higher the reliability of the foaming material to play the crucial role of energy-absorption as a buffer material.

\section{Conclusions}

In this report, a novel TPE material blended by PPB and EPDM and crosslinked by high-energy electron beam irradiation technology is successfully prepared, where the foaming process achieved by using an eco-friendly sc- $\mathrm{CO}_{2}$. The following conclusions can be drawn through the study of the properties and applications of this prepared novel TPE material and its foaming materials:

(1) PPB and EPDM are similar in molecular structure and have excellent compatibility. Microstructural study of the etched brittle section concludes that the two phases of the blend material can reach uniform dispersion (on the micron-scale). The increased EPDM content in EPDM/PPB foam would lead to the decline of mechanical properties such as hardness and tensile strength; however, the increase of irradiation crosslinking would enhance the same, and at the higher EPDM content, the more obvious the lifting effect has been observed. This is because EPDM contains more unsaturated groups which are more affected by irradiation crosslinking. In addition, the repeated processing performance test results of the TPE material showed that at higher PPB content, a very less mechanical property loss caused by repeated processing. Therefore, PPB component provided the repeatable processing performance of TPE material.

(2) With sc- $\mathrm{CO}_{2}$ fluid as the physical foaming agent, TPE materials irradiated by PPB and EPDM phases were prepared into microcellular foaming materials. Through the observation of the microstructure of foam materials with brittle section, it could be found that the increase of EPDM content leads to the decrease of the foam size, foaming ratio, and foaming performance. Proper crosslinking can improve the melt strength of the TPE material during foaming, which enhances the coating ability of the material to the gas, and improves the size of the bubbles along with the foaming ratio of the material. However, excessive crosslinking will lead to the increase of melt viscosity, the decrease of fluidity, the increase of resistance in the growth process of bubbles, and the decrease of bubble size and the foaming ratio of TPE materials. Therefore, PPB component also provides the main foaming properties of TPE materials.

(3) Compared with pure PPB foaming materials, the TPE materials mixed with EPDM have outstanding resistance to repeated compression, which is due to the good resilience provided by the crosslinked EPDM components. The cyclic compression test results of the TPE foaming material showed that the increase in EPDM content 
reduces the variation of delay loss of the TPE material, hence the repeated compression resistance of the material improved, and the reliability of the material as a buffer increased. However, the relative reduction of PPB component content will lead to the reduction of energy loss, so the energy-absorbed during the material compression process will increase. The TPE foaming material with EPDM/PPB: 60/40, can be used as the potential best foam for the application of buffer energy-absorbing. This TPE can be used according to the environment in the process of actual use with reasonable demand and the durability of materials and to satisfy the needs of a variety of buffer environment, which expand the application range of the prepared material.

\section{References}

[1] Mills N.: Polymer foams handbook: Engineering and biomechanics applications and design guide. Elsevier, (2007).

[2] Lee S. T.: Introduction: Polymeric foams, mechanisms, and materials. in 'Polymeric foams' (eds.: Lee S-T., Ramesh N. S.) CRC Press, Washington, 15-29 (2004).

[3] Tomasko D. L., Li H., Liu D., Han X., Wingert M. J., Lee L. J., Koelling K. W.: A review of $\mathrm{CO}_{2}$ applications in the processing of polymers. Industrial and Engineering Chemistry Research, 42, 6431-6456 (2003). https://doi.org/10.1021/ie030199z

[4] Yetkin S. H., Unal H., Mimaroglu A., Findik F.: Influence of process parameters on the mechanical and foaming properties of PP polymer and PP/TALC/EPDM composites. Polymer-Plastics Technology and Engineering, 52, 433-439 (2013).

https://doi.org/10.1080/03602559.2012.748802

[5] Klempner D., Frisch K. C.: Handbook of polymeric foams and foam technology. Hanser, New York (1991).

[6] Saiz-Arroyo C., de Saja J. A., Velasco J. I., RodríguezPérez M. Á.: Moulded polypropylene foams produced using chemical or physical blowing agents: Structureproperties relationship. Journal of Materials Science, 47, 5680-5692 (2012).

https://doi.org/10.1007/s10853-012-6357-7

[7] Tsivintzelis I., Pavlidou E., Panayiotou C.: Biodegradable polymer foams prepared with supercritical $\mathrm{CO}_{2}-$ ethanol mixtures as blowing agents. The Journal of Supercritical Fluids, 42, 265-272 (2007).

https://doi.org/10.1016/j.supflu.2007.02.009

[8] López-Periago A. M., Domingo C.: Features of supercritical $\mathrm{CO}_{2}$ in the delicate world of the nanopores. The Journal of Supercritical Fluids, 134, 204-213 (2018). https://doi.org/10.1016/j.supflu.2017.11.011
[9] Jacobs L. J. M., Kemmere M. F., Keurentjes J. T. F.: Sustainable polymer foaming using high pressure carbon dioxide: A review on fundamentals, processes and applications. Green Chemistry, 10, 731-738 (2008). https://doi.org/10.1039/b801895b

[10] Di Maio E., Mensitieri G., Iannace S., Nicolais L., Li W., Flumerfelt R. W.: Structure optimization of polycaprolactone foams by using mixtures of $\mathrm{CO}_{2}$ and $\mathrm{N}_{2}$ as blowing agents. Polymer Engineering and Science, 45, 432-441 (2005). https://doi.org/10.1002/pen.20289

[11] Ewing A. V., Gabrienko A. A., Semikolenov S. V., Dubkov K. A., Kazarian S. G.: How do intermolecular interactions affect swelling of polyketones with a differing number of carbonyl groups? An in situ ATRFTIR spectroscopic study of $\mathrm{CO}_{2}$ sorption in polymers. The Journal of Physical Chemistry C, 119, 431-440 (2015). https://doi.org/10.1021/jp510208e

[12] Radhakrishna G., Dugad R., Gandhi A.: Bimodal microcellular morphology evaluation in ABS-foamed composites developed using step-wise depressurization foaming process. Polymer Engineering and Science, 6, 113-131 (2019).

https://doi.org/10.1002/pen.25265

[13] Guo Y., Hossieny N., Chu R. K. M., Park C. B., Zhou N.: Critical processing parameters for foamed bead manufacturing in a lab-scale autoclave system. Chemical Engineering Journal, 214, 180-188 (2013). https://doi.org/10.1016/j.cej.2012.10.043

[14] Nofar M., Küçük E. B., Batı B.: Effect of hard segment content on the microcellular foaming behavior of TPU using supercritical $\mathrm{CO}_{2}$. The Journal of Supercritical Fluids, 153, 104590/1-104590/17 (2019). https://doi.org/10.1016/j.supflu.2019.104590

[15] Hossieny N. J., Barzegari M. R., Nofar M., Mahmood S. H., Park C. B.: Crystallization of hard segment domains with the presence of butane for microcellular thermoplastic polyurethane foams. Polymer, 55, 651662 (2014).

https://doi.org/10.1016/j.polymer.2013.12.028

[16] Di Maio E., Kiran E.: Foaming of polymers with supercritical fluids and perspectives on the current knowledge gaps and challenges. The Journal of Supercritical Fluids, 134, 157-166 (2018). https://doi.org/10.1016/j.supflu.2017.11.013

[17] Berejka A. J., Eberle C.: Electron beam curing of composites in North America. Radiation Physics and Chemistry, 63, 551-556 (2002). https://doi.org/10.1016/S0969-806X(01)00553-9

[18] Liu P., Liu D., Zou H., Fan P., Xu W.: Structure and properties of closed-cell foam prepared from irradiation crosslinked silicone rubber. Journal of Applied Polymer Science, 113, 3590-3595 (2009). https://doi.org/10.1002/app.30341 
[19] Yu C-T., Lai C-C., Wang F-M., Liu L-C., Liang W-C., Wu C-L., Chiu J-C., Liu H-C., Hsiao H-T., Chen C-M.: Fabrication of thermoplastic polyurethane (TPU)/thermoplastic amide elastomer (TPAE) composite foams with supercritical carbon dioxide and their mechanical properties. Journal of Manufacturing Processes, 48, 127-136 (2019).

https://doi.org/10.1016/j.jmapro.2019.09.022

[20] Malinowski R., Stepczyńska M., Raszkowska-Kaczor A., Żuk T.: Some effects of foaming of the poly(butylene adipate- $c o$-terephthalate) modified by electron radiation. Polymers for Advanced Technologies, 29, 1117-1122 (2018).

https://doi.org/10.1002/pat.4223

[21] Frounchi M., Dadbin S., Panahinia F.: Comparison between electron-beam and chemical crosslinking of silicone rubber. Nuclear Instruments and Methods in Physics Research Section B: Beam Interactions with Materials and Atoms, 243, 354-358 (2006). https://doi.org/10.1016/j.nimb.2005.09.013

[22] Bik J., Głuszewski W., Rzymski W. M., Zagórski Z. P.: EB radiation crosslinking of elastomers. Radiation Physics and Chemistry, 67, 421-423 (2003). https://doi.org/10.1016/S0969-806X(03)00078-1

[23] Ishida S., Nagasaki R., Chino K., Dong T., Inoue Y.: Toughening of poly (L-lactide) by melt blending with rubbers. Journal of Applied Polymer Science, 113, 558 566 (2009).

https://doi.org/10.1002/app.30134

[24] Bartczak Z., Argon A. S., Cohen R. E., Weinberg M.: Toughness mechanism in semi-crystalline polymer blends: I. High-density polyethylene toughened with rubbers. Polymer, 40, 2331-2346 (1999).

https://doi.org/10.1016/S0032-3861(98)00445-5

[25] Burgisi G., Paternoster M., Peduto N., Saraceno A.: Toughness enhancement of polyamide 6 modified with different types of rubber: The influence of internal rubber cavitation. Journal of Applied Polymer Science, 66, 777-787 (1997).

https://doi.org/10.1002/(SICI)10974628(19971024)66:4<777::AID-APP18>3.0.CO;2-O

[26] Coran A. Y., Patel R.: Rubber-thermoplastic compositions. Part IV. Thermoplastic vulcanizates from various rubber-plastic combinations. Rubber Chemistry and Technology, 54, 892-903 (1981). https://doi.org/10.5254/1.3535842

[27] Coran A. Y., Patel R.: Rubber-thermoplastic compositions. Part III. Predicting elastic moduli of melt mixed rubber-plastic blends. Rubber Chemistry and Technology, 54, 91-100 (1981). https://doi.org/10.5254/1.3535800

[28] Lopattananon N., Wangpradit N., Nakason C., Kaesaman A.: Effect of rubber composition on foaming and properties of EVA/NR/PP thermoplastic vulcanisates (TPVs). Journal of Rubber Research, 17, 80-95 (2014).
[29] Luo P., Wen S., Prakashan K., Zhang Z-X., Sinha T. K., Kim J. K.: Physico-mechanical properties of NBR/ CPVC blend vulcanizates and foams. Journal of Vinyl and Additive Technology, 25, 182-188 (2019).

https://doi.org/10.1002/vnl.21651

[30] Han D-H., Choi M-C., Jeong J-H., Choi K-M., Kim HS.: Properties of acrylonitrile butadiene rubber (NBR)/ poly(lactic acid) (PLA) blends and their foams. Composite Interfaces, 23, 771-780 (2016). https://doi.org/10.1080/09276440.2016.1170518

[31] Xin Z. X., Zhang Z. X., Pal K., Kim K-J., Kang D. J., Kim J. K., Bang D-S.: Microcellular structure of PP/ waste rubber powder blends with supercritical $\mathrm{CO}_{2}$ by foam extrusion process. Journal of Cellular Plastics, 45, 499-514 (2009). https://doi.org/10.1177/0021955X09342937

[32] da Silva A. L. N., Coutinho F. M. B.: Some properties of polymer blends based on EPDM/PP. Polymer Testing, 15, 45-52 (1996).

https://doi.org/10.1016/0142-9418(95)00012-7

[33] Coran A. Y., Patel R.: Rubber-thermoplastic compositions. Part I. EPDM-polypropylene thermoplastic vulcanizates. Rubber Chemistry and Technology, 53, 141150 (1980).

https://doi.org/10.5254/1.3535023

[34] Li Q., Zhao J-C., Liu W-B., Yuan M-H.: Analysis of the wrinkle of an automobile weather-strip seal in bending. Journal of Macromolecular Science Part B: Physics, 56, 124-133 (2017).

https://doi.org/10.1080/00222348.2017.1274104

[35] Jolfaei A. F., Gavgani J. N., Jalali A., Goharpey F.: Effect of organoclay and compatibilizers on microstructure, rheological and mechanical properties of dynamically vulcanized EPDM/PP elastomers. Polymer Bulletin, 72, 1127-1144 (2015).

https://doi.org/10.1007/s00289-015-1328-1

[36] Xu C., Zheng Z., Wu W., Wang Z., Fu L.: Dynamically vulcanized PP/EPDM blends with balanced stiffness and toughness via in-situ compatibilization of MAA and excess $\mathrm{ZnO}$ nanoparticles: Preparation, structure and properties. Composites Part B: Engineering, 160, 147-157 (2019).

https://doi.org/10.1016/j.compositesb.2018.10.014

[37] Lin Y., Chen H., Chan C-M., Wu J.: High impact toughness polypropylene $/ \mathrm{CaCO}_{3}$ nanocomposites and the toughening mechanism. Macromolecules, 41, 92049213 (2008).

https://doi.org/10.1021/ma801095d

[38] Li Y., Yao Z., Chen Z-H., Qiu S-L., Zeng C., Cao K.: Rheological evidence of physical cross-links and their impact in modified polypropylene. Industrial and Engineering Chemistry Research, 52, 7758-7767 (2013). https://doi.org/10.1021/ie400809z

[39] Kim D. Y., Cha J. H., Seo K. H.: Effects of chain extender on properties and foaming behavior of polypropylene foam. RSC Advances, 9, 25496-25507 (2019). https://doi.org/10.1039/c9ra04824c 
[40] Jia E., Zhao S., Shangguan Y., Zheng Q.: A facile fabrication of polypropylene composites with excellent low-temperature toughness through tuning interfacial area between matrix and rubber dispersion by silica nanoparticles located at the interface. Composites Science and Technology, 184, 107846/1-107846/7 (2019). https://doi.org/10.1016/j.compscitech.2019.107846

[41] Nofar M., Tabatabaei A., Sojoudiasli H., Park C. B., Carreau P. J., Heuzey M-C., Kamal M. R.: Mechanical and bead foaming behavior of PLA-PBAT and PLAPBSA blends with different morphologies. European Polymer Journal, 90, 231-244 (2017).

https://doi.org/10.1016/j.eurpolymj.2017.03.031

[42] Balaji A. B., Ratnam C. T., Khalid M., Walvekar R.: Effect of electron beam irradiation on thermal and crystallization behavior of PP/EPDM blend. Radiation Physics and Chemistry, 141, 179-189 (2017). https://doi.org/10.1016/j.radphyschem.2017.07.001
[43] Uthaipan N., Jarnthong M., Peng Z., Junhasavasdikul B., Nakason C., Thitithammawong A.: Effects of crosslinked elastomer particles on heterogeneous nucleation of isotactic PP in dynamically vulcanized EPDM/PP and EOC/PP blends. Journal of Polymer Research, 24, 118/1-118/13 (2017). https://doi.org/10.1007/s10965-017-1279-3

[44] Kim B. C., Hwang S. S., Lim K. Y., Yoon K. J.: Toughening of PP/EPDM blend by compatibilization. Journal of Applied Polymer Science, 78, 1267-1274 (2000). https://doi.org/10.1002/10974628(20001107)78:6<1267::AID-APP130>3.0.CO;2-B

[45] Bagheri H., Nekoomanesh M., Hakim S., Jahani Y., Tan S. H., Fan Z. Q.: Rheology of polypropylene/poly(ethylene-co-propylene) in-reactor alloy. Polymer Science Series A, 58, 283-291 (2016). https://doi.org/10.1134/S0965545X16020024

[46] Yoshiga A., Otaguro H., Parra D. F., Lima L. F. C. P., Lugao A. B.: Controlled degradation and crosslinking of polypropylene induced by gamma radiation and acetylene. Polymer Bulletin, 63, 397-409 (2009). https://doi.org/10.1007/s00289-009-0102-7 